Buletin Ilmiah Math, Stat, dan Terapannya (Bimaster)

Volume 08, No. 1 (2019), hal 11-20.

\title{
GRAF PERFECT DAN GRAF IMPERFECT PADA BEBERAPA GRAF
}

\author{
Zakiah, Helmi, Fransiskus Fran
}

INTISARI

Graf perfect adalah suatu graf $G$ dengan setiap $H$ subgraf induksi dari $G$ memenuhi $\omega(H)=\chi(H)$, sedangkan jika terdapat $H$ sehingga $\chi(H)>\omega(H)$ maka $G$ disebut graf imperfect. Terdapat beberapa graf yang pada kondisi tertentu merupakan graf perfect dan pada kondisi yang lain merupakan graf imperfect. Pada tulisan ini dibahas tentang graf perfect dan graf imperfect pada beberapa graf yaitu graf sikel $\left(C_{n}\right)$, graf roda $\left(W_{n}\right)$, dan graf helm $\left(H_{n}\right)$. Untuk $C_{3}, C_{2 n}, n \geq 2, W_{3}, W_{2 n}, n \geq 2, H_{3}, H_{2 n}, n \geq 2$ merupakan graf perfect, sedangkan untuk $C(2 n+1), n \geq 2, W_{(2 n+1)}, n \geq 2$, dan $H_{(2 n+1)}, n \geq 2$ merupakan graf imperfect.

Kata Kunci : subgraf induksi, pewarnaan graf, bilangan clique, bilangan kromatik

\section{PENDAHULUAN}

Graf pertama kali digunakan untuk merepresentasikan masalah jembatan Konigsberg pada tahun 1736. Pada tahun tersebut, seorang matematikawan Swiss bernama Euler berhasil memecahkan masalah jembatan Konigsberg dengan memodelkan masalah ini ke dalam bentuk graf. Daratan (titiktitik yang dihubungkan oleh jembatan) dinyatakannya sebagai simpul dan jembatan dinyatakannya sebagai sisi [1].

Salah satu materi pada Teori Graf yang berkembang saat ini adalah tentang pewarnaan graf. Pewarnaan graf adalah suatu pemberian warna pada salah satu elemen-elemennya (simpul, sisi, atau wilayah) sehingga lemen-elemen yang saling bertetangga memiliki warna yang berbeda. Simpulsimpul yang bertetangga dalam suatu graf $G$ dinamakan clique, sedangkan jumlah simpul maksimum dari clique dinamakan bilangan clique, dinotasikan $\omega(G)$. Pewarnaan graf khususnya pewarnaan simpul telah banyak diterapkan dalam berbagai bidang antara lain permasalahan traffic light, masalah penjadwalan dan lain-lain. Jumlah warna minimum yang digunakan untuk mewarnai simpul graf disebut bilangan kromatik yang dinotasikan $\chi(G)$. Terdapat satu konsep pada teori graf yang menghubungkan antara bilangan clique dan bilangan kromatik yaitu graf perfect dan graf imperfect. Graf perfect adalah suatu graf $G$ dengan setiap $H$ subgraf induksi dari $G$ memenuhi $\omega(H)=\chi(H)$ [2], sedangkan jika terdapat $H$ sehingga $\chi(H)>\omega(H)$ maka $G$ disebut graf imperfect [3]. Terdapat beberapa graf yang pada kondisi tertentu merupakan graf perfect dan pada kondisi yang lain merupakan graf imperfect. Graf tersebut diantaranya adalah graf sikel, graf roda, dan graf helm. Oleh karena itu, penelitian ini membahas tentang bagaimana kondisi graf perfect dan graf imperfect pada graf sikel, graf roda, dan graf helm.

\section{TEORI GRAF}

Sebelum membahas tentang graf perfect dan graf imperfect terlebih dahulu diberikan definisi dari graf, subgraf, subgraf induksi, clique dan bilangan clique, pewarnaan simpul graf, dan bilangan kromatik yang digunakan sebagai dasar untuk pembahasan selanjutnya.

Definisi 1 [1] Graf $G$ didefinisikan sebagai pasangan himpunan $(V, E)$, ditulis dengan $G=(V, E)$, yang dalam hal ini $V$ adalah himpunan tidak kosong dari simpul-simpul (vertices atau node) dan $E$ adalah himpunan sisi (edges atau arcs) yang menghubungkan sepasang simpul. 
Berikut ini diberikan contoh graf $G$ berdasarkan Definisi 1.

Contoh 2 Misalkan diberikan sebuah graf $G$ dengan himpunan simpul $V=\{A, B, C, D, E\}$, dan himpunan sisi $E=\left\{e_{1}, e_{2}, e_{3}, e_{4}, e_{5}\right\}$ dengan $e_{1}=(A, B), e_{2}=(A, E), e_{3}=(B, E), e_{4}=(D, E)$, $e_{5}=(B, C), e_{6}=(C, D)$ diperlihatkan seperti Gambar 1 berikut.

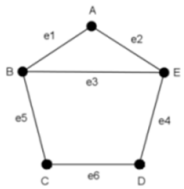

Gambar 1 Graf $G$ dengan 5 buah simpul dan 6 buah sisi

Pembahasan selanjutnya adalah subgraf dan subgraf induksi pada suatu graf $G$ yang dituangkan dalam Definisi 3 dan Definisi 4 berikut.

Definisi 3 [6] Graf $H$ adalah subgraf dari $G$ jika dan hanya jika $V(H) \subseteq V(G)$ dan $E(H) \subseteq E(G)$.

Definisi 4 [4] Subgraf induksi dari $G$ adalah $G^{\prime}$ jika untuk setiap $x, y \in V^{\prime}$ berlaku $(x, y) \in E^{\prime}$ jika dan hanya jika $(x, y) \in E$.

Berdasarkan Definisi 4 subgraf induksi diperoleh dengan cara menghapus simpul beserta sisi yang bersisian dengan simpul tersebut.

Contoh 5 Berikut ini diberikan salah satu contoh subgraf, bukan subgraf, dan salah satu subgraf induksi dari Gambar 1.

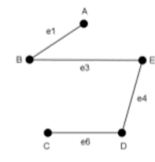

(a)

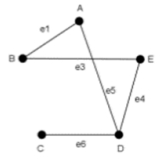

(b)

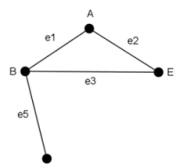

(c)

Gambar 2 Contoh subgraf pada $(a)$, bukan subgraf pada $(b)$, dan subgraf induksi pada $(c)$

Jumlah subgraf induksi dari suatu graf $G$ dapat diketahui dengan menggunakan Proposisi yang dituangkan dalam Proposisi 6 berikut.

Proposisi 6 Banyaknya subgraf induksi dari suatu graf $G$ dapat diketahui dengan menggunakan rumus berikut

$n=$ jumlah simpul

Jumlah subgraf induksi graf $G=2^{n}-1$

Pembahasan selanjutnya adalah clique dan bilangan clique yang dituangkan dalam Definisi 7 berikut.

Definisi 7 [5] Clique dari graf $G=(V, E)$ adalah himpunan $K \subseteq V$ sedemikian sehingga setiap pasangan simpul di $K$ dihubungkan oleh suatu sisi. Bilangan clique adalah jumlah clique terbesar dari graf $G$ dan dinotasikan dengan $\omega(G)$.

Contoh 8 Berdasarkan Gambar 1 clique terbesar dari graf $G$ adalah sebanyak tiga simpul yaitu $\{A, B, E\}$, maka bilangan cliquenya adalah tiga, dinotasikan $\omega(G)=3$.

Definisi 9 [2] Pewarnaan simpul pada graf $G=(V, E)$ adalah pemetaan $c: V \rightarrow S$ dengan $S$ ditentukan sebagai himpunan warna seperti $\{$ merah, biru, hijau,... $\}$ atau himpunan bilangan asli 
$\{1,2,3, \ldots\}$ sedemikian sehingga $c(x) \neq c(y)$ ketika $x$ dan $y$ adalah dua simpul yang saling bertetangga. Jika $S$ memilki suatu $k$ elemen, maka c disebut suatu pewarnaan-k di $G$.

Berdasarkan Definisi 9 berikut ini adalah contoh pewarnaan simpul graf.

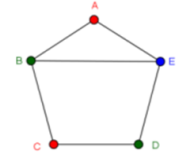

Gambar 3 Pewarnaan simpul graf

Dalam pewarnaan simpul graf, warna yang digunakan adalah seminimal mungkin yang dinamakan dengan bilangan kromatik. Berikut diberikan definisi bilangan kromatik.

Definisi 10 [1] Jumlah warna minimum yang dapat digunakan untuk mewarnai simpul disebut bilangan kromatik graf $G$, dinotasikan dengan $\chi(G)$.

Contoh 11 Berdasarkan Definisi 10 dan dari Gambar 3 maka bilangan kromatik dari graf $G$ adalah tiga, dinotasikan $\chi(G)=3$.

Berikut ini diberikan proposisi bahwa setiap clique dari graf $G$ memperoleh warna yang berbeda oleh fungsi pewarnaan $c$.

Proposisi 12 [4] Misalkan $G=(V, E)$ dan $K$ merupakan clique dari $G$. Jika c adalah suatu pewarnaan dari $G$, maka fungsi $c$ memberikan warna yang berbeda pada setiap simpul $K$.

Berdasarkan Proposisi 12 berikut ini diberikan proposisi yang menerangkan bahwa bilangan kromatik dari suatu graf $G$ selalu lebih dari atau sama dengan bilangan clique seperti yang dituangkan dalam Proposisi 13.

Proposisi 13 [4] Untuk setiap graf $G$, maka $\chi(G) \geq \omega(G)$. Dengan kata lain bilangan kromatik dari graf $G$ selalu lebih dari atau sama dengan bilangan clique.

Berdasarkan Proposisi 12 dan Proposisi 13, terdapat hubungan antara bilangan clique dan bilangan kromatik. Reinhard Diestel dalam bukunya yang berjudul Graph Theory membahas suatu materi yang menghubungkan antara bilangan clique dan bilangan kromatik yang dinamakan dengan graf perfect. Sementara Chris Godsil dan Gordon Royle dalam bukunya yang berjudul Algebraic Graph Theory membahas materi tentang graf imperfect. Adapun definisi dari graf perfect dan graf imperfect dituangkan dalam Definisi 14 dan Definisi 15 berikut.

Definisi 14 [2] Sebuah graf G adalah perfect jika untuk setiap subgraf induksi $H$ dari G memiliki bilangan kromatik dan bilangan clique yang sama $\chi(H)=\omega(H)$.

Definisi 15 [3] Graf imperfect adalah graf yang memiliki bilangan kromatik lebih besar dari bilangan clique $\chi(H)>\omega(H)$.

Sebelum membahas tentang graf perfect dan graf imperfect pada graf sikel, graf roda, dan graf helm, perlu diketahui bahwa graf lengkap dan open chain merupakan graf perfect yang nantinya digunakan sebagai acuan dalam pembuktian graf perfect dan graf imperfect yang lain. 
Definisi 16 [6] Graf $G$ disebut graf lengkap jika setiap simpul di G terhubung ke seтиa simpul lainnya. Graf lengkap dengan $n$ buah simpul dilambangkan dengan $K_{n}$. Setiap simpul pada $K_{n}$ berderajat $n-1$.

Terdapat hubungan antara subgraf induksi dari graf lengkap dengan graf lengkap yang dituangkan dalam Lemma 17 berikut.

Lemma 17 [4] Setiap subgraf induksi dari graf lengkap adalah graf lengkap.

Contoh 18 Misalkan $n=5$ maka diperoleh graf lengkap $K_{5}$ seperti pada Gambar 4 berikut.

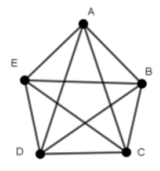

Gambar 4 Graf lengkap $K_{5}$

Berdasarkan Gambar 4 beberapa subgraf induksi dari graf lengkap $K_{5}$ menghasilkan bentuk graf seperti pada Gambar 5 berikut.
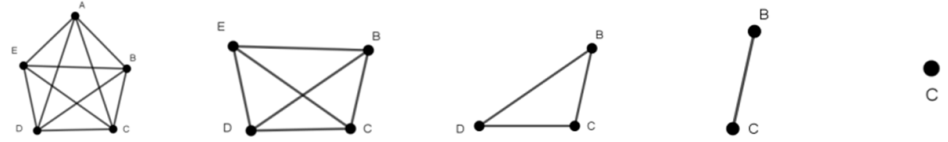

Gambar 5 Subgraf induksi graf lengkap $K_{5}$

Berdasarkan Lemma 17, Peter Ballen dalam tulisannya yang berjudul Perfect Graphs and The Perfect Graph Theorems menuliskan suatu teorema yang dituangkan dalam Teorema 19 berikut.

Teorema 19 [4] Setiap graf lengkap adalah graf perfect.

Bukti. Teorema ini akan dibuktikan dengan menggunakan induksi matematika berdasarkan jumlah simpul dari graf lengkap. Graf lengkap dengan satu simpul $K_{1}$ merupakan graf perfect karena $\omega\left(K_{1}\right)=\chi\left(K_{1}\right)$ dan $K_{1}$ tidak memiliki subgraf induksi yang lain selain dirinya sendiri. Asumsikan bahwa graf lengkap dengan jumlah simpul $n$ adalah graf perfect. Misalkan $K_{n+1}$ adalah graf lengkap dengan jumlah simpul $n+1$. Misalkan $H$ adalah subgraf induksi dari $K_{n+1}$. Semua subgraf induksi dari graf lengkap adalah graf lengkap berdasarkan Lemma 17. Jika $H$ adalah subgraf induksi dari $K_{n+1}$ dan $H \neq K_{n+1}$ maka $H$ adalah graf lengkap dengan jumlah simpul $n$ atau kurang dari $n$ dan $H$ merupakan graf perfect berdasarkan asumsi. Jadi $\omega(H)=\chi(H)$. Selanjutnya, jika $H=K_{n+1}$ maka $\omega\left(K_{n+1}\right)=\chi\left(K_{n+1}\right)=n+1$.

Contoh 20 Misalkan $n=4$ maka diperoleh graf lengkap $K_{4}$ seperti Gambar 6 berikut.

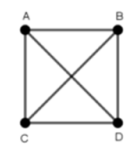

Gambar 6 Graf lengkap $K_{4}$

Berdasarkan Gambar 6 subgraf induksi dari graf lengkap $K_{4}$ adalah graf lengkap berdasarkan Lemma 17. Subgraf induksi graf lengkap $K_{4}$ untuk $H=K_{4}$ atau dirinya sendiri clique terbesarnya adalah empat maka $\omega\left(K_{4}\right)=4$. Selanjutnya warna minimum yang diperlukan untuk mewarnai simpul graf lengkap $K_{4}$ seperti pada Gambar 7 berikut. 


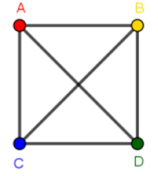

Gambar 7 Hasil pewarnaan simpul graf lengkap $K_{4}$

Berdasarkan Gambar 7 warna minimum yang diperoleh untuk mewarnai graf lengkap $K_{4}$ adalah sebanyak empat warna maka bilangan kromatiknya adalah empat, dinotasikan $\chi\left(K_{4}\right)=4$ sehingga diperoleh untuk $H=K_{4}$ maka $\omega\left(K_{4}\right)=\chi\left(K_{4}\right)=4$. Jadi graf lengkap $K_{4}$ merupakan graf perfect.

Berikutnya perlu diketahui bahwa open chain juga merupakan graf perfect yang akan dituangkan dalam sebuah teorema. Sebelum membahas tentang itu terlebih dahulu diberikan definisi open chain.

Definisi 21 [4] Misalkan $G=(V, E)$. Suatu $G$ adalah open chain jika $V=\left\{v_{1}, v_{2}, \ldots, v_{n}\right\}$ dan $E=\left\{\left(v_{1}, v_{2}\right),\left(v_{2}, v_{3}\right), \ldots,\left(v_{n-1}, v_{n}\right)\right\}$.

Setelah mengetahui definisi open chain, berikutnya ditunjukkan bahwa open chain merupakan graf perfect seperti yang dituangkan dalam Teorema 22 berikut.

Teorema 22 [4] Setiap open chain adalah graf perfect.

Bukti. Misalkan $G=(V, E)$ adalah open chain. Misalkan $H$ adalah subgraf induksi dari $G$, maka terdapat dua kemungkinan dari $H$ berdasarkan ketetanggaannya.

Kasus 1. $H$ tidak memuat simpul yang bertetangga.

Jika $H$ tidak memuat simpul yang bertetangga maka $\omega(H)=1$. Fungsi pewarnaannya dimisalkan dengan $c\left(v_{i}\right)=$ merah untuk semua $v \in H$, maka untuk semua $v \in H$ memiliki fungsi 1-pewarnaan, dan bilangan kromatiknya adalah satu, dinotasikan $\chi(H)=1$. Sehingga diperoleh $\omega(H)=\chi(H)=1$, dengan kata lain $H$ merupakan graf perfect. Dapat dilihat pada Gambar 8 berikut.

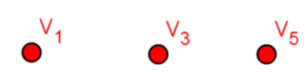

Gambar $8 H$ tidak memuat simpul yang bertetangga

Kasus 2. $H$ memuat simpul yang bertetangga.

Open chain yang memuat simpul bertetangga memiliki clique terbesarnya yaitu dua karena hanya ada dua simpul yang saling bertetangga, maka bilangan cliquenya adalah dua, dinotasikan $\omega(H)=2$. Fungsi $c$ untuk pewarnaan simpulnya dapat didefinisikan seperti berikut :

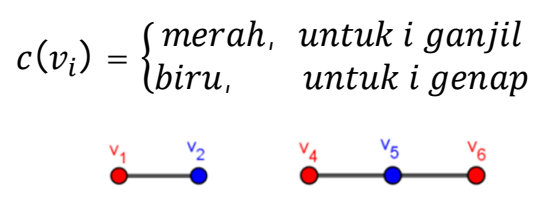

Gambar $9 H$ memuat simpul yang bertetangga

sehingga fungsi $c$ pada $H$ adalah sebanyak dua pewarnaan, dan bilangan kromatiknya adalah dua, dinotasikan $\chi(H)=2$. Maka diperoleh $\omega(H)=\chi(H)=2$. Dengan kata lain $H$ adalah graf perfect.

Pembahasan berikutnya adalah kondisi graf perfect dan graf imperfect pada graf sikel. Sebelum membahas tentang itu, terlebih dahulu perlu diketahui definisi dari graf sikel yang dituangkan dalam Definisi 23 berikut. 
Definisi 23 [1] Graf sikel adalah graf terhubung yang setiap simpulnya berderajat dua. Graf sikel dengan $n$ simpul dilambangkan dengan $C_{n}$. Jika simpul-simpul pada $C_{n}$ adalah $v_{1}, v_{2}, v_{3}, \ldots, v_{n}$, maka sisi-sisinya adalah $\left(v_{1}, v_{2}\right),\left(v_{2}, v_{3}\right), \ldots,\left(v_{n-1}, v_{n}\right)$, dan $\left(v_{n}, v_{1}\right)$. Dengan kata lain ada sisi dari simpul terakhir $v_{n}$ yang terhubung ke simpul pertama $v_{1}$.

Graf sikel pada kondisi tertentu merupakan graf perfect namun pada kondisi tertentu merupakan graf imperfect. Seperti yang dituangkan pada Teorema 24 berikut.

Teorema 24 Misalkan $C_{n}$ merupakan graf sikel dengan $n$ merupakan banyaknya simpul, maka terdapat dua kondisi pada graf sikel berdasarkan jumlah simpulnya.

a. Graf sikel $C_{3}$ dan setiap graf sikel $C_{2 n}$ adalah graf perfect.

b. Jika $n \geq 2$, maka $\chi\left(C_{2 n+1}\right)>\omega\left(C_{2 n+1}\right)$.

Bukti. Diberikan $C_{n}$ adalah graf sikel dengan jumlah simpul sebanyak $n$, maka kondisi dari $C_{n}$ dijelaskan seperti berikut.

a. Graf sikel $C_{3}$ setiap simpulnya mempunyai sisi ke semua simpul lainnya. Hal ini serupa dengan definisi graf lengkap yang artinya graf sikel $C_{3}$ merupakan graf lengkap $K_{3}$. Graf lengkap berdasarkan Teorema 19 merupakan graf perfect, maka graf sikel $C_{3}$ juga merupakan graf perfect.

Selanjutnya misalkan $G=(V, E)$ adalah graf sikel $C_{2 n}$. Misalkan $H$ adalah subgraf induksi dari $G$ dan $H=C_{2 n}$, clique terbesar dari $C_{2 n}$ memiliki jumlah simpul maksimum yang saling bertetangga yaitu sebanyak dua simpul maka bilangan cliquenya adalah dua, dinotasikan $\omega\left(C_{2 n}\right)=2$. Pewarnaan simpul pada graf sikel $C_{2 n}$ dapat dilakukan dengan cara menetapkan warna pertama misalkan warna merah untuk simpul ganjil, dan warna kedua misalkan warna hijau untuk simpul genap. Cara seperti ini dilakukan dan menghasilkan dua simpul yang bertetangga memiliki warna yang berbeda, maka warna minimum yang dapat diberikan untuk $H=C_{2 n}$ adalah 2 warna, dinotasikan $\chi\left(C_{2 n}\right)=2$. Jadi diperoleh $\omega\left(C_{2 n}\right)=\chi\left(C_{2 n}\right)=2$, sehingga terbukti untuk $H=C_{2 n}$ merupakan graf perfect.

Selanjutnya untuk $H \neq C_{2 n}$, maka $H$ akan menghasilkan graf yang berbentuk graf lengkap dan subgraf induksi dari open chain. Graf lengkap dan open chain berdasarkan Teorema 19 dan Teorema 22 telah terbukti merupakan graf perfect maka untuk setiap subgraf induksi $H$ dan $H \neq C_{2 n}$ merupakan graf perfect. Jadi terbukti bahwa setiap graf sikel $C_{2 n}$ merupakan graf perfect.

b. Graf $G$ pada graf sikel $C_{2 n+1}, n \geq 2$ memiliki jumlah simpul maksimum yang saling bertetangga adalah dua maka bilangan cliquenya adalah dua, dinotasikan $\omega\left(C_{2 n+1}\right)=2$. Pewarnaan simpul pada graf sikel $C_{2 n+1}$ dilakukan dengan cara dimisalkan pada graf sikel $C_{2 n+1}$ ditetapkan nomor $V_{1}$ sampai $V_{2 n+1}$ pada simpul graf, kemudian warna pertama misalkan warna merah ditetapkan ke simpul ganjil dan warna kedua misalkan warna hijau ke simpul genap. Cara seperti ini dilakukan agar dua simpul yang bertetangga memiliki warna yang berbeda, akan tetapi simpul $V_{2 n+1}$ dan simpul $V_{1}$ dihubungkan oleh sebuah sisi atau saling bertetangga sehingga kedua simpul ini tidak dapat diwarnai dengan warna yang sama, maka dibutuhkan warna ketiga misalkan warna biru. Jadi warna minimum yang diperoleh untuk graf sikel $C_{2 n+1}$ adalah sebanyak 3 warna, dinotasikan $\chi\left(C_{2 n+1}\right)=3$. Sehingga diperoleh $\chi\left(C_{2 n+1}\right)>\omega\left(C_{2 n+1}\right)$. Jadi $C_{2 n+1}$ merupakan graf imperfect.

Contoh 25 Misalkan $n=3$ maka diperoleh graf sikel $C_{6}$ seperti pada Gambar 10 berikut.

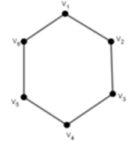

Gambar 10 Graf sikel $C_{6}$ 
Berdasarkan Gambar 10 untuk subgraf induksi $H$ dan $H=C_{6}$, bilangan cliquenya adalah dua, dinotasikan $\omega\left(C_{6}\right)=2$. Pewarnaan simpul pada graf sikel $C_{6}$ diperlihatkan seperti pada Gambar 11 berikut.

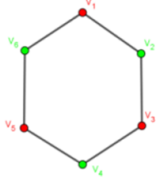

Gambar 11 Hasil pewarnaan simpul graf sikel $C_{6}$

Berdasarkan Gambar 11, bilangan kromatiknya adalah dua, dinotasikan $\chi\left(C_{6}\right)=2$. Sehingga diperoleh $\omega\left(C_{6}\right)=\chi\left(C_{6}\right)=2$. Dengan kata lain terbukti bahwa untuk subgraf induksi $H$ dan $H=C_{6}$ merupakan graf perfect.

Selanjutnya untuk $H \neq C_{6}$, berdasarkan Proposisi 6 jumlah subgraf induksi untuk graf sikel $C_{6}$ berjumlah 63 graf. Oleh sebab itu, sangat tidak efektif untuk mengeceknya satu persatu. Sehingga berikut ini diperlihatkan beberapa bentuk subgraf induksi dari graf sikel $C_{6}$ yang diuraikan seperti berikut.

1. Subgraf induksi yang menghasilkan bentuk graf lengkap seperti pada Gambar 12 berikut.

\section{$v^{v_{1}}$}

Gambar 12 Subgraf induksi $C_{6}$ dengan Satu simpul

2. Subgraf induksi yang menghasilkan bentuk subgraf induksi dari open chain seperti pada Gambar 13 berikut.

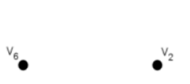

(a) (b)

Gambar 13 Subgraf induksi dari open chain yang memuat simpul yang tidak bertetangga

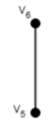

(a)

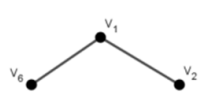

$(\boldsymbol{b})$

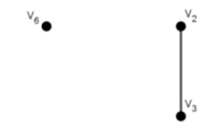

(c)

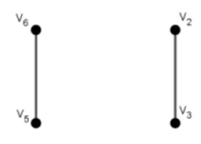

(d)

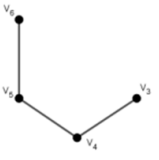

$(\boldsymbol{e})$

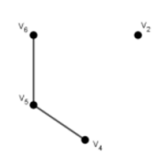

$(\boldsymbol{f})$

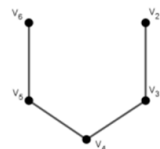

$(\boldsymbol{g})$

Gambar 14 Subgraf induksi dari open chain yang memuat simpul yang bertetangga

Berdasarkan uraian di atas subgraf induksi dari $C_{6}$ pada nomor 1 membentuk graf lengkap, dan nomor 2, subgraf induksinya membentuk subgraf induksi dari open chain, berdasarkan hal tersebut maka subgraf induksi dari graf sikel $C_{6}$ untuk $H \neq C_{6}$ merupakan graf perfect. Jadi graf sikel $C_{6}$ merupakan graf perfect.

Contoh 26 Misalkan $n=3$ maka diperoleh $C_{7}$ seperti pada Gambar 15 berikut. 


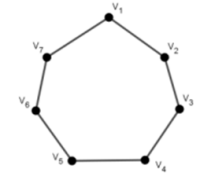

\section{Gambar 15 Graf sikel $C_{7}$}

Berdasarkan Gambar 15, bilangan cliquenya adalah dua, dinotasikan $\omega\left(C_{7}\right)=2$. Pewarnaan simpulnya diperlihatkan pada Gambar 16 berikut.

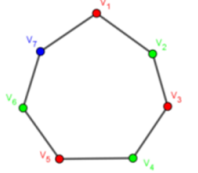

Gambar 16 Hasil pewarnaan simpul graf sikel $C_{7}$

Berdasarkan Gambar 16 bilangan kromatiknya adalah tiga dinotasikan $\chi\left(C_{7}\right)=3$. Sehingga diperoleh $\chi\left(C_{7}\right)>\omega\left(C_{7}\right)$. Dengan kata lain graf sikel $C_{7}$ merupakan graf imperfect.

Pembahasan selanjutnya adalah graf perfect dan graf imperfect pada graf roda. Sebelumnya terlebih dahulu diberikan definisi dari graf roda.

Definisi 27 [7] Graf roda $W_{n}$ adalah graf yang memuat sikel yang setiap simpul pada sikel tersebut terhubung langsung dengan titik pusat.

Adapun kondisi graf roda yang merupakan graf perfect dan graf imperfect seperti yang dituangkan dalam Teorema 28 berikut.

Teorema 28 Misalkan $W_{n}$ merupakan graf roda dengan $n$ merupakan banyaknya simpul, maka terdapat dua kondisi pada graf roda berdasarkan jumlah simpulnya.

a. Graf roda $W_{3}$ dan setiap graf roda $W_{2 n}, n \geq 2$ adalah graf perfect.

b. Jika $n \geq 2$, maka $\chi\left(W_{2 n+1}\right)>\omega\left(W_{2 n+1}\right)$.

Contoh 29 Misalkan $n=3$ maka diperoleh graf roda $W_{6}$ seperti Gambar 17 berikut.

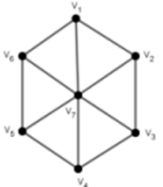

Gambar 17 Graf roda $W_{6}$

Berdasarkan Gambar 17 untuk subgraf induksi $H$ dan $H=W_{6}$, bilangan cliquenya adalah tiga, dinotasikan $\omega\left(W_{6}\right)=3$. Pewarnaan simpul pada graf roda $W_{6}$ diperlihatkan pada Gambar 18 berikut.

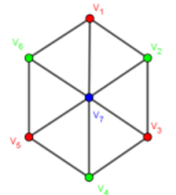

Gambar 18 Hasil pewarnaan simpul graf roda $W_{6}$ 
Berdasarkan Gambar 18 bilangan kromatiknya adalah tiga, dinotasikan $\chi\left(W_{6}\right)=3$. Sehingga diperoleh $\omega\left(W_{6}\right)=\chi\left(W_{6}\right)=3$. Dengan kata lain terbukti bahwa subgraf induksi $H$ dan $H=W_{6}$ adalah graf perfect.

Contoh 30 Misalkan $n=2$ maka diperoleh graf roda $W_{5}$ seperti Gambar 19 berikut.

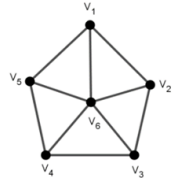

\section{Gambar 19 Graf roda $W_{5}$}

Berdasarkan Gambar 19 bilangan cliquenya adalah tiga, dinotasikan $\omega\left(W_{5}\right)=3$. Pewarnaan simpul pada graf roda $W_{5}$ diperlihatkan seperti pada Gambar 20 berikut.

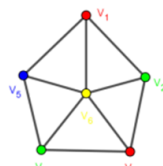

Gambar 20 Hasil pewarnaan simpul graf roda $W_{5}$

Berdasarkan Gambar 20 bilangan kromatiknya adalah empat, dinotasikan $\chi\left(W_{5}\right)=4$. Sehingga diperoleh $\chi\left(W_{5}\right)>\omega\left(W_{5}\right)$. Dengan kata lain graf roda $W_{5}$ merupakan graf imperfect.

Definisi 31 [8] Graf helm $H_{n}$ adalah graf yang didapatkan dari sebuah graf roda dengan menambahkan sisi anting-anting pada setiap simpul di sikel luar.

Adapun kondisi graf helm yang merupakan graf perfect dan graf imperfect dituangkan dalam Teorema 32 berikut.

Teorema 32 Misalkan $H_{n}$ merupakan graf helm dengan $n$ merupakan banyaknya simpul, maka terdapat dua kondisi pada graf helm berdasarkan jumlah simpulnya.

a. Graf helm $\mathrm{H}_{3}$ dan setiap graf helm $\mathrm{H}_{2 n,}, n \geq 2$ adalah graf perfect.

b. Jika $n \geq 2$, maka $\chi\left(H_{2 n+1}\right)>\omega\left(H_{2 n+1}\right)$.

Contoh 33 Misalkan $n=2$ maka diperoleh graf helm $H_{4}$ seperti pada Gambar 21 berikut.

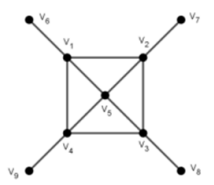

\section{Gambar 21 Graf helm $H_{4}$}

Berdasarkan Gambar 21 bilangan cliquenya adalah tiga, dinotasikan $\omega\left(H_{4}\right)=3$. Selanjutnya pewarnaan simpul pada graf helm $H_{4}$ diperlihatkan seperti pada Gambar 22 berikut.

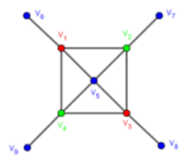

Gambar 22 Hasil pewarnaan simpul graf helm $H_{4}$ 
Berdasarkan Gambar 22 bilangan kromatiknya adalah tiga, dinotasikan $\chi\left(H_{4}\right)=3$. Sehingga diperoleh $\omega\left(H_{4}\right)=\chi\left(H_{4}\right)=3$. Jadi terbukti untuk subgraf induksi $H$ dan $H=H_{4}$ merupakan graf perfect.

Contoh 34 Misalkan $n=3$ maka diperoleh $H_{7}$ seperti pada Gambar 23 berikut.

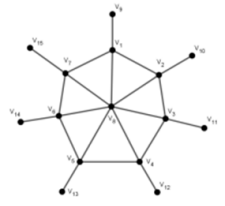

Gambar 23 Graf helm $H_{7}$

Berdasarkan Gambar 23, bilangan cliquenya adalah tiga, dinotasikan $\omega\left(H_{7}\right)=3$. Pewarnaan simpul pada graf helm $H_{7}$ diperlihatkan seperti pada Gambar 24 berikut.

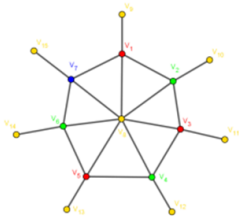

Gambar 24 Hasil pewarnaan simpul graf helm $\mathrm{H}_{7}$

Berdasarkan Gambar 24 bilangan kromatiknya adalah empat, dinotasikan $\chi\left(H_{7}\right)=4$. Sehingga diperoleh $\chi\left(H_{7}\right)>\omega\left(H_{7}\right)$. Dengan kata lain graf helm $H_{7}$ merupakan graf imperfect.

\section{PENUTUP}

Berdasarkan pembahasan yang telah dipaparkan, maka dapat ditarik kesimpulan, yaitu:

1. Graf lengkap, open chain, graf sikel $C_{3}$ dan setiap graf sikel $C_{2 n}, n \geq 2$, graf roda $W_{3}$ dan setiap graf roda $W_{2 n}, n \geq 2$, graf helm $H_{3}$ dan setiap graf helm $H_{2 n}, n \geq 2$ merupakan graf perfect.

2. Graf sikel $C_{2 n+1}, n \geq 2$, graf roda $W_{2 n+1,}, n \geq 2$, dan graf helm $H_{2 n+1,}, n \geq 2$ merupakan graf imperfect.

\section{DAFTAR PUSTAKA}

[1] Munir R. Matematika Diskrit Ed ke-3. Bandung: Informatika; 2010.

[2] Diestel R. Graph Theory. New York: Springer-Verlag; 2001.

[3] Godsil C, Royle G. Algebraic Graph Theory. New York: Springer-Verlag; 2000.

[4] Ballen P. Perfect Graphs and The Perfect Graph Theorems. Philadelpia: University of Pennsylvania; 2014.

[5] Regin JC. Using Contraint Programming to Solve the Maximum Clique Problem. France: Falbonne; 1681.

[6] Vasudev C. Combinatorics and Graph Theory. India: New Age International (P) Ltd; 2007.

[7] Masni. Pewarnaan Sisi pada Graf yang Berhubungan dengan Sikel. Jurnal MSA. 2014; (2):69-75.

ZAKIAH

HELMI

FRANSISKUS FRAN
: Jurusan Matematika FMIPA UNTAN, Pontianak zakiahuntan@gmail.com

: Jurusan Matematika FMIPA UNTAN, Pontianak helmi132205@yahoo.co.id : Jurusan Matematika FMIPA UNTAN, Pontianak Frandly88@gmail.com 